Filieri R. How Young Chinese Consumers Choose among Different Smartphone Brands: The Importance of Socio-cultural and Marketing Factors. In: Dey, B; Sorour, K; Filieri, R, ed. ICTs in Developing Countries : Research, Practices and Policy Implications. Houndmills, Basingstoke, Hampshire: Palgrave Macmillan, 2016, pp.59-73.

\section{Copyright:}

Filieri R, How Young Chinese Consumers Choose among Different Smartphone Brands: The Importance of Socio-cultural and Marketing Factors, 2016, Palgrave Macmillan, reproduced with permission of Palgrave Macmillan.

This extract is taken from the author's original manuscript and has not been edited. The definitive, published, version of record is available here: http://dx.doi.org/10.1057/9781137469502 4.

DOI link to chapter:

http://dx.doi.org/10.1057/9781137469502 4

Date deposited:

$12 / 09 / 2016$

Embargo release date:

27 July 2019

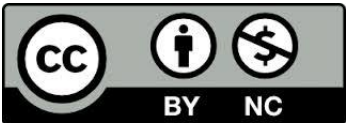

This work is licensed under a Creative Commons Attribution-NonCommercial 3.0 Unported License 


\title{
How Young Chinese Consumers Choose Among Different Smartphone brands: The Importance of Socio-cultural and Marketing Factors
}

Dr. Raffaele Filieri, Senior Lecturer Northumbria University

\begin{abstract}
Consumers buy technology not just for the functional use but increasingly for the symbolic functions associated to its use. In this paragraph we examine Chinese consumer purchase intentions of smartphone brands. Smartphone is a new technology device of mobile phone communication which has become part of people lifestyle. Smartphone sales have registered a sharp increase in sales over the past decade in China, in particular the Apple iPhone has dominated the market for a long time. Consumers buy Apple iPhone not only for its technical functions, apps, and durability, but also because of the aesthetics of the product such as the style and design of the smartphone as well as the social status that the product can communicate. The study has adopted the qualitative method of investigation and interviews with Chinese Smartphone users as a research tool. The results highlight the importance of brand awareness, image and brand innovativeness for Chinese consumers.

Keywords: China, Mianzi, adoption, smartphones, TAM, IDT, TPB

\section{Introduction}

In the twenty-first century, smartphones appear to be viewed as a necessity for the majority of consumers across all dimensions of age, gender or education level (Persaud and Azhar, 2012). In the last few years, smartphone penetration has grown such that smartphones have become a life companion for many customers who use them multiple times each day to perform a wide range of activities, such as checking emails, chatting with friends, browsing the internet, managing businesses, purchasing products and booking services, and so forth.
\end{abstract}


Smartphone use is expected to increase exponentially in the years to come; with growing access to advanced technology, both the use and desire for new applications are increasing and more than $30 \%$ of mobile owners globally use smartphones (Fergusson, 2012). China is the world's largest smartphone consumer market, and the second highest in the world for smartphone penetration rate with $66 \%$ of Chinese people owning smartphones (Nielsen, 2013). Despite the increased significance of this emerging market, no previous research has empirically investigated Chinese consumers' preference for smartphone brands thus this study is designed to address this gap.

A smartphone is more than a simple mobile phone as it adds new functions such as an Internet connection, a camera, and a large data storage capacity. Although Apple Inc. is considered the company that invented the smartphone with its iPhone model, nowadays the global market is populated by several competing brands, such as Samsung, Nokia, BlackBerry, Sony, HTC, LG, Xiaomi, Huawei, and many more. In the presence of such trends, there is a growing need to understand the ways in which Chinese consumers choose among different smartphone brands and the circumstances under which one brand may be chosen instead of another one.

A smartphone belongs to the family of high-technology products, "products that are the result of technology and which require substantial shifts in behavior of at least one member of the product usage channel" (Gardner et al., 2000, p. 1053). Existing theories for explaining consumer behaviour in relation to high-technology products mainly focus on consumer adoption of high-tech products. Examples of these theories include the Technology Acceptance Model (TAM) (Davis, 1989), the Theory of Reasoned Action (TRA) (Fishbein and Ajzen, 1975), or the Theory of Planned Behaviour (TPB) (Ajzen, 1991), or Innovation Diffusion Theory (IDT) (Rogers, 2003). These theories are effective in terms of explaining why consumers decide to adopt (purchase) a new technology (i.e. smartphone) instead of an 
existing one (i.e. mobile phone) (e.g., Park and Chen, 2007; Chen and Chen, 2009; Joo and Sang, 2013; Kim et al., 2014); however, they may not be effective in explaining why consumers choose a specific high-technology brand over alternatives available in the marketplace. The aim of the present study, therefore, is to address this gap by developing a new conceptual framework which will be effective in explaining the factors that directly influence consumer choice of smartphone brands. Thus, this paper contributes to international marketing literature on branding high-technology products in China and consumer behaviour with a focus on smartphone brands.

Despite the exponential growth of smartphone technology and its rapid adoption by vast numbers of consumers, to date, no research has investigated the factors that influence consumer's choice decision regarding smartphone brands as previous studies have analysed antecedents of consumer purchase intentions for mobile value-added services (Wang and Li, 2012)or analysed the marketing opportunities offered by smartphones and consumer attitudes towards mobile advertising (Hein et al., 2011; Jun and Lee, 2007, Merisavo et al., 2007; Gao et al., 2013).

To summarise, the purpose of this study is to explore the factors that drive Chinese consumers' preference towards smartphone brands. In view of the lack of research on this topic and the need to develop a new theoretical framework to explain consumer smartphone brand choice, this exploratory study has adopted a qualitative method of investigation consisting of interviews exploring Chinese consumer's preference over smartphone brands.

\section{Emerging markets and smartphone brands}

With a huge population and a growing number of middle class consumers that have high purchasing power, emerging markets are becoming ever more attractive as a prime target for multinational companies. As many western consumer markets have matured and there has been little or no growth, global brand managers are frequently turning their attention to fast- 
growing countries in Africa, Asia and Latin America. How such companies enter and compete with local players in emerging markets represents a key challenge. It has been stated that there is a need to obtain fresh insights to help further our understanding of brand management and consumption in emerging markets (Burgess and Steenkamp, 2006). This study focuses on an emerging market, namely China and attempts to understand the drivers of consumers' choice of smartphone brands.

Although smartphones have become fundamental accessories in many people's everyday lives, very little is known about consumers' product choice of Smartphone brands. Even less is known about Chinese consumers' purchase intentions for smartphone brands. There are several reasons to focus on the Chinese market: first, among the emerging market, it is the one who is driving the smartphone industry as the world's largest smartphone consumer market, the second, country in the world for smartphone penetration rate, and $66 \%$ of Chinese people own a smartphone (Nielsen, 2013).

A smartphone is a high-technology product, which can be defined as "products that are the result of technology and which require substantial shifts in behavior of at least one member of the product usage channel" (Gardner et al., 2000, p. 1053).

Existing theories for explaining consumer behaviour with high-technology products mainly focus on consumer motivations to adopt a new technology. Examples of these theories include the TAM (Davis, 1989), the TRA (Fishbein and Ajzen, 1975), the TPB (Ajzen, 1991), or the IDT (Rogers, 2003). These theories have been used extensively by scholars to predict consumer technology adoption behaviour even in the context of smartphones (e.g., Park and Chen, 2007; Chen and Chen, 2009; Joo and Sang, 2013; Kim et al., 2014). For instance, Park and Chen (2007) integrate IDT and TAM to explain the determinants of smartphone adoption by medical doctors and nurses, similarly Chen and Chen (2009) use the same framework to investigate employee adoption of smartphones in a delivery service company, highlighting 
the importance of factors like self-efficacy and perceived ease of use on behavioral intention to use the technology. Joo and Sang (2013) also use TAM to measure the impact of factors such as perceived ease of use and usefulness (and their antecedents) on Korean consumers' intentions to use a smartphone, while Ting et al. (2011) have investigated the factors that drive dependency on smartphones in Malaysia. These studies found that the aforementioned factors explain users' adoption of technologies. TAM implies the adoption of factors such as ease of use, usefulness, self-efficacy; IDT includes relative advantage, compatibility, testability, complexity, observable. However, we believe that these factors do not fully explain why consumers choose a specific high-technology product brand over the alternatives available in the marketplace.

From the review of the academic literature we can clearly see that the existing literature is mainly focused on mobile phone choice or smartphone adoption and no study, to date, has investigated why and how consumers choose among different smartphone brands. As discussed above, a Smartphone is a very different product when compared with a standard mobile phone; as a result, factors that can affect the choice of mobile phones might not be the same as for smartphone.

To summarise, this research will explore the factors that influence Chinese consumers' brand choice for Smartphone products through using a qualitative approach based on face-to face interviews.

\section{Methodology}

To date, no research has explored the factors that affect consumer choice regarding selection of a particular smartphone brand over alternatives available. Since the nature of the study is exploratory with the aim of building a new theoretical framework to explain consumers' choice of smartphone brands, a qualitative methodology based on in-depth interviews was chosen as the most appropriate approach (Glaser and Strauss, 1967). 
The in-depth interview method was adopted as it can yield a deeper understanding of the participants' own perceptions, opinions, and feelings about brand choice from which understanding researchers can inductively develop an empirically grounded theory (Glaser and Strauss, 1967; Kvale, 2007). This method would permit to gain an in-depth understanding of Chinese consumers' underlying motives, and attitudes towards smartphone brand choice, which aim to develop a theoretical model uncovering the antecedents of smartphone brand choice in the Chinese Smartphone market (Kvale, 2007).

The sampling technique was based on a convenience, purposive sample and participants owning a smartphone were recruited among students, colleagues, friends, and acquaintances. A total of 25 face-to-face interviews were conducted within a period of six months, mainly in Chinese (Mandarin and Cantonese). In order to take into account the influence of price on consumer decision making (e.g. Karjaluoto et al., 2005), the participants selected had different levels of income (personal or family), from less than 10.000 Renminbi (RMB) (Chinese currency) to over 20,000 per month. The total number of interviews was judged as sufficient for reaching theoretical saturation as additional interviews were adding no new insights (Strauss and Corbin, 1998; Kvale, 2007). The sample details are displayed in Table 1. Interviewees were Chinese students in the age bracket of 18-25, the majority of them come from affluent families with a monthly salary of over GBP 2,000, were born in the South or South-East of China, and are studying for their degree.

The interview protocol adopted was semi-structured and questions ranged from general questions asking participants to give a personal historic overview of their usage and ownership of mobile and smartphone brands over the years (including reasons for changing brand and usage of the smartphone models owned as well as the meanings they associated with the smartphone and the brand); to more specific questions referring to the motivation for purchase of the last smartphone brand (i.e.: What does this smartphone brand means to you? 
Why have you decided to purchase this specific brand? What is your opinion of this brand?). Interviews lasted between 40 to 55 minutes and were recorded digitally and later transcribed and translated into English. The translation was sampled and checked independently by a native Chinese speaker with professional qualifications in English language.

Codes were generated from consumer behaviour theory and open and axial coding were adopted to analyse the data (Strauss and Corbin, 1998). Open coding was used to shed light on the properties and dimensions of concepts in the dataset.

In order to check the validity and reliability of the index and sub-categories obtained, the researcher contacted three academics who did not participate in the interviews to test the inter-rater agreement.

Table 4-1. Respondents' profile

\begin{tabular}{|c|c|c|c|c|c|c|}
\hline Code & $\begin{array}{l}\text { Age } \\
\text { group }\end{array}$ & Gender & Education level & $\begin{array}{l}\text { Area from } \\
\text { China }\end{array}$ & $\begin{array}{l}\text { Parents monthly } \\
\text { Income } \\
\text { (in RMB) }\end{array}$ & Brand owned \\
\hline $\mathrm{R} 1$ & $23-25$ & Male & Postgraduate & South & 11,000 to 19,000 & iPhone4 \\
\hline $\mathrm{R} 2$ & $23-25$ & Male & Postgraduate & $\begin{array}{l}\text { South-East } \\
\text { coastal }\end{array}$ & $>20,000$ & iPhone5 \\
\hline R3 & $23-25$ & Male & Undergraduate & North & 11,000 to 19,000 & iPhone4 \\
\hline R4 & $26-30$ & Female & Postgraduate & South & $<10,000$ & $\begin{array}{l}\text { iPhone } \\
\text { Samsung Note }\end{array}$ \\
\hline R5 & $23-25$ & Male & Undergraduate & North-West & $<10,000$ & ZTE \\
\hline R6 & $23-25$ & Male & Postgraduate & South & $<10,000$ & iPhone5 \\
\hline R7 & $26-30$ & Male & $\begin{array}{l}\text { Postgraduate } \\
\text { (MBA) }\end{array}$ & Hong Kong & $>20,000$ & $\begin{array}{l}\text { iPhone, Samsung } \\
\text { Note }\end{array}$ \\
\hline R8 & $23-25$ & Male & Postgraduate & Taiwan & 11,000 to 19,000 & iPhone4 \\
\hline R9 & $23-25$ & Female & Postgraduate & South & $>20,000$ & iPhone, Samsung \\
\hline
\end{tabular}




\begin{tabular}{|c|c|c|c|c|c|c|}
\hline R10 & $23-25$ & Female & Postgraduate & South & 11,000 to 19,000 & iPhone 5 \\
\hline R11 & $18-22$ & Male & Postgraduate & South-East & $>20,000$ & HTC One \\
\hline & & & & costal & & \\
\hline R12 & $18-22$ & Female & Postgraduate & South & $>20,000$ & iPhone 4S \\
\hline R13 & $18-22$ & Female & Postgraduate & North & 11,000 to 19,000 & iPhone 4 \\
\hline R14 & $18-22$ & Female & Undergraduate & South & $>20,000$ & iPhone 5 \\
\hline R15 & $18-22$ & Female & Undergraduate & South & 11,000 to 19,000 & iPhone 5 \\
\hline R16 & $18-22$ & Male & Postgraduate & South & $>20,000$ & iPhone 4, 5 \\
\hline R17 & $18-22$ & Male & Postgraduate & South-East & $<10,000$ & Nokia N79 \\
\hline & & & & costal & & \\
\hline R18 & $18-22$ & Female & Undergraduate & South & 11,000 to 19,000 & iPhone 5 \\
\hline R19 & $18-22$ & Female & Postgraduate & South & $>20,000$ & iPhone 4 \\
\hline R20 & $18-22$ & Male & Undergraduate & South & $>20,000$ & iPhone 5 \\
\hline R21 & $18-22$ & Male & Undergraduate & South & $>20,000$ & iPhone 5 \\
\hline R22 & $23-25$ & Male & Postgraduate & North & 11,000 to 19,000 & iPhone 5 \\
\hline R23 & $23-25$ & Female & Postgraduate & South & $>20,000$ & iPhone 4 \\
\hline R24 & $23-25$ & Male & Postgraduate & South & 11,000 to 19,000 & iPhone 5 \\
\hline R25 & $23-25$ & Female & Postgraduate & South & $>20,000$ & iPhone 5 \\
\hline
\end{tabular}

\section{Results}

Although consumers may have different motivations to purchase a particular smartphone brand, we consistently found that some factors occur in most of the interviews.

The findings suggest three broad categories of antecedents of Chinese consumer choice of smartphone brands, which were classed in order of importance for the respondents (based on number of times mentioned): (1) brand/marketing, (2) socio-cultural, (3) product features. The dominant themes refer to the marketing influence dimension and include factors referring to the brand such as brand image, brand loyalty, brand popularity and the design and 
appearance of the smartphone product. The second in order of number of times mentioned refers to the socio-cultural influences dimension and includes factors such as social influences (friends and family) and 'mianzi' considerations, the individual's reputation and social position in others' eyes. The least mentioned factor referred to was the product dimension and this includes factors such as the safety and ease of use of the operating system, and ease of access to social media applications for social networking.

\section{Brand choice influencers}

\section{Social influence}

China is a collectivist society (Hofstede, 1980), namely Chinese individuals prioritize social well-being before individual well-being. The collectivist orientation is reflected in the Chinese family and kinship system (Yau, 1988). Chinese society has historically concentrated on group orientation and harmony in managing all interpersonal relations; as a result, Chinese consumers tend to value group decisions, order, and security in their purchase behaviors (Zhang et al., 2012).

Since traditional Chinese culture rests on kinship and family bonds (Yau, 1988), people rely on word-of-mouth communication to obtain credible product information with the belief that only 'bad' products or services need advertising (Gong et al., 2004).

From the interview data, it emerges that friends and family are a primary source of influence on smartphone brand choice decisions. Chinese consumers often rely more on face-to-face and electronic word-of-mouth respectively from their friends, family members or expert reviewers in professional websites because they are skeptical of traditional advertising messages. Moreover, it seems that friends' and family's advice and opinions are so influential that consumers tend to purchase the same products and brands without collecting much 
information about product features and functionality. Most of the participants would tend to ask their friends for suggestion or ask them how they feel after using a particular smart phone brand, and then adopt their recommendation and go straight away to the shop. If most of their friends think highly of, or own, a specific smart phone brand, Chinese consumers will trust them and take action based on their friends' recommendations:

"if most of my friends are using the same one, the one should be very good (R3)"

"every time I would like to purchase something, I will have to ask my friends for suggestion and recommendation $(R 9)$,"

\section{Brand popularity}

Through interviews we were able to identify a new concept referring to brand value, namely brand popularity. Chinese consumers tend to choose popular brands, those brands that are widespread in society. According to interviewees, a brand that is popular in the society is also associated with high quality because Chinese consumers think that the more popular a brand is in society, the higher will be its quality. Interviewees clearly articulated this concept in the discussions and respondents stated that they believe that a product/brand that is used by many

people must necessarily be good. The importance of the level of popularity of a brand may derive from Chinese respect for social norms and group orientation. Group orientation is concerned with a sense of community, solidarity and harmony in society where individuals co-exist among others (Tran et al., 2008). In summary, the more people purchase the same brand, the more it becomes popular in the social grouping or in society, which in turn exercises a strong influence on Chinese consumers' brand associations and preferences. In fact, the more widespread a brand 
is among their social circles the more it is perceived to be of high quality, thus influencing consumer choice:

"if it is popular and most people are using it, there should be some reasons behind that so many people are buying it... I will think this brand has a good reputation because a lot of people are buying the same brand... (R9)

\section{Brand image and loyalty}

Brand image and loyalty are components of the customer-based brand equity construct, which is also composed of other assets (liabilities), including perceived quality and brand awareness (Aaker, 1991; Keller, 1993; Cobb-Walgren et al., 1995). Chinese consumers in interviews highlight the former factors as critical criteria that they consider when they have to choose among different smartphone brands. Keller (1993, p. 3) defines brand image as "an overall perception of a brand derived from the brand associations held in consumer memory", while brand loyalty is defined as: "a deeply held commitment to rebuy or repatronise a preferred product or service consistently in the future, despite situational influences and marketing efforts having potential to cause switching behavior" (Oliver, 1997, p. 392). In this study we have found that brand image has a strong influence on Chinese consumers. From our interviews, we acknowledge that the image portrayed by the brand, together with brand loyalty, are both highly significant to Chinese consumers. A specific smartphone brand has the function of signaling socio-economic success, for this reason consumers will be more likely to consider a brand with a very positive reputation. Loyalty was particularly evident among Apple iPhone users:

"...because I like this brand, then I have a desire to buy it. Comparing iPhone with Samsung, I prefer to buy iPhone. It is because of the popularity and image of Apple brand...(R16) 
"I like all kind of Apple products which is another important reason for me to choose iPhone. If there are a lot of brands to choose, I am sure that I would like to choose Apple without any hesitation because I like this brand and what it represents...(R12)

\section{Design / appearance of the smartphone}

Design is an increasingly important criterion in relation to the functional features as the Smartphone has to look good (Luchs and Swan, 2011). Bloch (1995, p. 16) defines product design from a formal point of view as "a number of elements chosen and blended into a whole by the design team to achieve a particular sensory effect. Designers make choices regarding characteristics, such as shape, scale, tempo, proportion, materials, color, reflectiveness, ornamentation, and texture". Design is also viewed as a conscious effort to produce a product, service, or experience that combines both functionality and aesthetics (Mohr et al., 2010, p. 234). Nowadays, design of a new product must combine the criteria of being useful and aesthetically pleasing.

Based on our findings, smartphone innovative design has reached the top of the list in the criteria that Chinese consumers consider before purchasing a specific Smartphone brand. In this study, in terms of the design, participants referred to four key aspects of a Smartphone's design: screen size, color, weight, and aesthetics. These represent the most important aspects that Chinese consumers pay attention to when they select among different smartphone brands. Regarding aesthetics, there was agreement about the fact that an 'ugly Smartphone' was believed to be symbolic of a lack of style. As participants explained even though different people have different aesthetic standards, a smartphone design should look nice and attractive to be considered by Chinese consumers. It was said to be a good feeling when holding the Smartphone, which makes users feel fashionable and more confident: 
"The first eye sight for a product is the appearance, so, the design of a phone is important, and the appearance and design of the phone should be consistent with the overall image and perception of myself..." (R11)

\section{Mianzi}

Culture is defined by Hofstede (1991) as collective programming of the mind which distinguish the members of one group or category of people from another. Collective programming of the mind is different in different countries, where people share similar values within a certain national environment. In China, Chinese people follow the teachings of Confucius (Kung Fu Tzen), an ancient Chinese philosopher, whose influence spread out of China to other East Asian countries (Fang, 1999). One of the notions deriving from Confucianism is the notion of 'face', which implies maintaining one's public dignity and standing (Lee, 1990). The word 'Mianzi' or 'Face' or 'Mien-tsu' (Hong-Kong) is derived from Confucianism, which means consciousness of glory and shame; meanwhile, it represents the individual's reputation and social position in others' eyes (Hu, 1944). Mianzi stands for "the kind of prestige that is emphasized ... a reputation achieved through getting on in life, through success and ostentation" (Hu, 1944). On the one hand, Chinese consumers try to maintain their reputation (face) in front of significant others.

The findings of this study indicate that buying a specific smartphone brand can enhance face or enable Chinese consumers to not lose face in relation to others. Chinese consumers are afraid of losing face, experiencing social withdrawal, or feeling inferior towards their friends. Buying a cheap or unpopular smartphone brand is a risky decision (Gao, 1998). Interviewees clearly stated that they could feel embarrassed and humiliated in front of others if they were using a cheap smartphone brand or, interestingly, a Chinese brand. According to respondents, purchasing an expensive and popular smartphone brand enables them to gain or maintain face, which means it enables them to save face and be accepted and recognized by others. 
Owning an expensive smart phone fosters feelings of proudness and vanity in Chinese consumers. By owning an expensive and well-reputed smartphone brand the Chinese consumer believes s/he can increase the amount of mianzi, which is a function of his or her social status.

"if I am not using that kind of Smartphone, I may feel upset and may lead to isolation, and if it is only myself who is not using it, I will feel a sense of inferiority. And if I use the same good Smartphone as my friends, it would be more comfortable and it will be easier to socialise with them...” (R1)

\section{Smartphone Features}

Smartphone are equipped with multimedia features, which include a digital camera, operating system, apps, interactivity tools, storage, games, mp3 player among the others. With regard to the functions and features, only a few participants declared that they selected a specific smartphone brand because of its features. Therefore, interviewees on the whole took the view that excellence of a particular brand of smartphone in one or more features (e.g. a high performing camera) does not outweigh the benefits or attractiveness of a brand that is popular among or recommended by their friends.

In terms of the specific functions, interviewees declared that they were interested in social communications functions such as the ease of access to social communication apps (i.e. Wechat, Sina Weibo, Qzone...), which is in line with a recent McKinsey survey revealing that the country has by far the world's most active social-media population (Chiu et al., 2013), while others mentioned simple functions, such as personal notes, camera, music, calendar, which can be found in a normal mobile phone. This shows that, in the first instance, consumers favored some brands not for their perceived quality, expected performance or for the innovativeness of the smartphone functions, but rather on the basis of the smartphone's 
capability to access social media and put them in contact with significant others (family and friends).

Some respondents, especially the iPhone users, also mentioned the ease of use of the phone's operating system and the usefulness of its applications. However, these were not deciding factors to choose one smartphone brand over another; rather they were discovered only after the decision has been made.

"I have tried to use iPhone's IOS system, it is simple to use without such complex processes when you download... while with other smartphones some applications and software need to be taken from some website and there you can get some virus... while the iPhone or the Macbook will rarely get viruses, therefore I decided for a higher quality and safe Smartphone." (R3)

\section{Discussion}

China has become the world's largest consumer market for smartphones, therefore it is paramount that marketers understand what drives consumer choice in this country.

As distinct from previous studies that focus on mobile phone products from Western countries (e.g., Wilska, 2003; Karjaluoto et al., 2005; Petruzzelis, 2010) or that attempt to explain the factors driving new technology (smartphone) adoption through IDF and TAM theory (e.g., Park and Chen, 2007; Chen and Chen, 2009; Joo and Sang, 2013; Kim et al., 2014), this study has been carried out to develop a new theoretical framework to explain Chinese consumer choice in relation to smartphone brands.

The results of this study highlight that Chinese smartphone brand choice is affected by a number of drivers including: marketing influences, such as brand image and popularity, design and appearance of the smartphone; socio-cultural factors, such as friends and parents' 
advice and mianzi considerations; and at last product considerations, in terms of smartphone features.

The results of this study advance the international marketing literature for branding hightechnology products in China by providing a new theoretical framework that promises to be more effective than existing technology acceptance models (e.g., TAM, TRA, IDF) and the brand equity framework (Aaker, 1991) in predicting Chinese consumer choice of smartphone brands.

With this study we have demonstrated that a high-technology product such as a smartphone is considered a status symbol among Chinese consumers; it symbolizes belongingness to a specific social class or group, and it is used to create distinction between a social group (wealthy consumers) and another one (less affluent consumers). Comparing the results with previous studies of Western consumers (e.g., Wilska, 2003; Karjaluoto et al., 2005), where the mobile phone symbolized a part of personal identity by Finnish consumers, it is clear from the results of this study that Chinese consumers' motivations towards smartphone brand choice are more socially- oriented, in that a smartphone is purchased to fulfil their need for social integration, harmony and social inclusion. Among Chinese consumers a smartphone brand mainly symbolizes belongingness to a collectivist culture and it is used to enable the individual consumer to be more integrated with this collective.

As such, for Chinese consumers it is paramount that a smartphone brand is well-known and widespread in society, is fashionable, it is used by their friends and is able to communicate the owner's social status and lifestyle.

This study's findings are also different from those of Joo and Sang (2013) who found that Korean adult users of Apple's iPhone are affected primarily by motivations based on instrumental and goal-oriented use while young Chinese consumers are directed by both the need of social inclusion and pressure to conform. Thus, social status considerations, 
ostentatious consumption, and brand image and popularity are important among these Chinese consumers, who are strongly influenced by their social environment and by their culture rather than by individual considerations about what the phone can do for them.

Brand considerations are key in Chinese consumer choice of smartphone brands. This study enabled us to conceptualize a new construct which might be used to measure brand equity, namely brand popularity. The concept of brand popularity is different from brand awareness, which is the closest construct available in branding literature. Brand awareness refers to an assessment of a consumer capability to recognize a brand or logo among other competing brands or to recall it (Keller, 1993). However, brand popularity is a different concept and refers to a consumer's assessment of how many people are already using the brand, namely how widespread a brand is in a particular society or social grouping. According to our findings, Chinese consumers have high levels of awareness of brands available in the market and most smartphone brands are well-known, in that consumers can recall and recognize them; however, a product is popular only when many people are buying and using it. The importance of brand popularity may derive from Chinese respect for social norms and group orientation. Group orientation is concerned with a sense of community, solidarity and harmony in society where individuals co-exist among others (Tran et al., 2008). Chinese consumers have a profound respect of social norms, which make them decide to consume the brands or products that are more popular not only among their peers but also in the society in general. Therefore, what is trendy and popular in the social community or family a Chinese individual belongs to tends to have a strong influence in Chinese consumer preferences towards a specific Smartphone brand. The need to conform seems to be stronger than individual's evaluation of benefits and needs in relation to a high-technology product such as a smartphone. 


\section{References}

Aaker, D. A. (1991), Managing Brand Equity: Capitalizing on the Value of Brand Name, Free Press, New York, NY.

Abe, S., Bagozzi, R.P. and Sadarangani, P. (1996), "An investigation of construct validity and generalizability of the self-concepts: self-consciousness in Japan and the United States", Journal of International Consumer Marketing, Vol. 8 No. 3/4, pp. 97-123.

Ajzen, I. (1991), “The Theory of Planned Behavior", Organizational Behavior and Human Decision Processes, Vol. 50 No. 2, pp. 179-211.

Bloch, P.H. (1995), "Seeking the Ideal Form: Product Design and Consumer Response," Journal of Marketing, Vol. 59 No. 3, pp. 16-29.

Chen, J. and Kim, S.Y. (2013), “A Comparison of Chinese Consumers' Intentions to Purchase Luxury Fashion Brands for Self-Use and for Gifts”, Journal of International Consumer Marketing, Vol. 25 No. 1, pp. 29-44.

Chen, J.D.Y. and Chen, K. (2009), "The acceptance and diffusion of the innovative smart phone use: A case study of a delivery service company in logistics", Information \& Management, Vol. 46 No. 3, pp. 241-248.

Chiu, C., Lin, D. and Silverman, A. (2013), "High influence: China's social media boomiConsumer: Life Online compendium", McKinsey \& Company, available at: http://www.mckinseyonmarketingandsales.com/high-influence-chinas-social-mediaboom (accessed 10 February 2013).

Cobb-Walgren, C.J. and Ruble, C.A. (1995), "Brand equity, brand preference, and purchase intent”, Journal of Advertising, Vol. 24 No. 3, pp. 25-41.

Davis, F.D. (1989), "Perceived usefulness, perceived ease of use, and user acceptance of information technology”, MIS Quarterly, Vol. 13 No. 3, pp. 319-339.

Fang, T. (1999), Chinese Business Negotiating Styles, Sage, Thousand Oaks, CA. 
Fergusson, J. (2012), "10 trends in mobile", Warc Trends, available at: http://www.warc.com/Content/ContentViewer.aspx?MasterContentRef=9aa99e7b$\underline{\text { abb6-4c76-a8a1-6bca15aa1917\&CID=A98432\&PUB=WARC-TRENDS }}$ (accessed 10 March 2014).

Fishbein, M. and Ajzen, I. (1975), Belief, Attitude, Intention and Behavior: An Introduction to Theory and Research, Addison-Wesley, Reading, MA.

Gao, T.T., Rohm, A.J., Sultan, F. and Pagani, M. (2013), "Consumers un-tethered: A threemarket empirical study of consumers' mobile marketing acceptance", Journal of Business Research, Vol. 66 No. 12, pp. 2536-2544.

Gao, G. (1998), "An initial analysis of the effects of face and concern for "other" in Chinese interpersonal communication”, International Journal of Intercultural Relation, Vol. 22 No. 4, pp. 467-482.

Gardner, D.M., Johnson, F., Lee, M. and Wilkinson, I. (2000), “A contingency approach to marketing high technology products”, European Journal of Marketing, Vol. 34 No. 9, pp. 1053-1077.

Glaser, B.G. and Strauss, A.L. (1967), The Discovery of Grounded Theory: Strategies for Qualitative Research, Aldine Publishing Company, Chicago.

Gong, W., Li, Z.G. and Li, T. (2004), "Marketing to China's youth: a cultural transformation Perspective”, Business Horizons, Vol. 47 No. 6, pp.41-50.

Hein, W., O’Donohoe, S. and Ryan, A. (2011), "Mobile phones as an extension of the participant observer's self: Reflections on the emergent role of an emergent technology", Qualitative Market Research: An International Journal, Vol. 14 No. 3, pp. 258-273.

Ho, D.Y.F. (1976), “On the Concept of Face”, American Journal of Sociology, Vol. 81 No. 4, pp. $867-884$. 
Hofstede, G. (1991), Cultures and organizations: software of the mind, McGraw-Hill, New York, NY.

Hu, H.C. (1944), “The Chinese Concept of Face”, American Anthropologist, Vol. 46 No. 1, pp. 45-64.

Joo, J. and Sang, Y. (2013), “Exploring Koreans' smartphone usage: An integrated model of the technology acceptance model and uses and gratifications theory", Computers in Human Behavior, Vol. 29 No. 6, pp. 2512-2518.

Jun, J. and Lee, S. (2007), "Mobile Media Use and Its Impact on Consumer Attitudes towards Mobile Advertising”, International Journal of Mobile Marketing, Vol. 2 No. 1, pp. 5058.

Karjaluoto, H., Karvonen, J., Kesti, M., Koivumäki, T., Manninen, M., Pakola, J., Ristola, A. and Salo, J. (2005), "Factors Affecting Consumer Choice of Mobile Phones: Two Studies from Finland”, Journal of Euromarketing, Vol. 14 No. 3, pp. 59-81.

Keller, K.L. (1993), “Conceptualizing, measuring, and managing customer-based brand equity", Journal of Marketing, Vol. 57 No. 1, pp. 1-22.

Kim, D., Chun, H. and Lee, H. (2014), "Determining the factors that influence college students' adoption of smartphones", Journal of the Association for Information Science and Technology, Vol. 65 No. 3, pp. 578-588.

Kvale, S. (2008). Doing interviews. Sage, London.

Lee, C. (1990), "Modifying an American consumer behavior model for consumers in confucian culture: the case of fishbein behavioral intention model", Journal of International Consumer Marketing, Vol. 3 No. 1, pp. 27-50.

Lee, S.Y. (2014), "Examining the factors that influence early adopters' smartphone adoption: The case of college students", Telematics and Informatics, Vol. 31 No. 2, pp. 308-318. 
Liu, C.M. (2002), "The effects of promotional activities on brand decision in the cellular telephone industry", Journal of Product \& Brand Management, Vol. 11 No. 1, pp. 4251.

Luchs, M. and Swan, K.S. (2011), "Perspective: The Emergence of Product Design as a Field of Marketing Inquiry”, Journal of Product Innovation Management, Vol. 28 No. 3, pp. $327-345$.

Merisavo, M., Kajalo, S., Karjaluoto, H., Virtanen, V., Salmenkivi, S., Raulas, M. and Leppäniemi, M. (2007), “An empirical study of the drivers of consumer acceptance of mobile advertising”, Journal of Interactive Advertising, Vol. 7 No. 2, pp. 41-50.

Mohr, J.J., Sengupta, S. and Slater, S.F. (2010), Marketing of high-technology products and innovations. Upper Saddle River, N.J, Pearson Prentice Hall.

Nielsen (2013), "How the Mobile Consumer Connects around the Globe", available at: http://www.nielsen.com/us/en/insights/news/2013/how-the-mobile-consumer-connectsaround-the-globe.html (accessed 10 March 2014).

Oliver, R. and Rust, R. (1997), “Customer Delight: Foundations, Findings, and Managerial Insight," Journal of Retailing, Vol. 73 No. 3, pp. 311-337.

Park, Y. and Chen, J.V. (2007), "Acceptance and adoption of the innovative use of smartphone”, Industrial Management \& Data Systems, Vol. 107 No. 9, pp. 1349-1365.

Persaud, A., Azhar, I. (2012), "Innovative mobile marketing via smartphones: Are consumers ready?”, Marketing Intelligence \& Planning, Vol. 30 Iss: 4, pp.418 - 443

Rogers, E.M. (2003), Diffusions of Innovations, 5th Ed, Free Press, New York, NY.

Strauss, A. and Corbin, J. (1998), Basics of qualitative research: Techniques and procedures for developing grounded theory, 2nd Ed. Sage, Thousand Oaks, CA. 
Ting, D.H., Lim, S.F., Patanmacia, T.S., Low, C.G. and Ker, G.C. (2011), “Dependency on smartphone and the impact on purchase behaviour", Young Consumers: Insight and Ideas for Responsible Marketers, Vol. 12 No. 3, pp. 193-203.

Tran, Q.V., To, N.T., Nguyen, C.B., Lam, M.D. and Tran., T.A. (2008), Co So Van Hoa Vietnam (Fundamentals of Vietnamese Culture), The Education Publisher (published in Vietnamese language), Hanai, Vietnam.

Wang, W.T. and Li, H.M. (2012), "Factors influencing mobile services adoption: a brandequity perspective", Internet Research, Vol. 22 No. 2, pp. 142-179.

Wilska, T.A. (2003), "Mobile phone use as part of young people's consumption styles", Journal of Consumer Policy, Vol. 26 No. 4, pp. 441-463.

Yau, O.H.M. (1988), "Chinese Cultural Values: Their Dimensions and Marketing Implications", European Journal of Marketing, Vol. 22 No. 5, pp. 44-57.

Zhang, H.P., Lu, Y., Shi, X.L., Tang, Z.M. and Zhao, Z.J. (2012), “Mood and social presence on consumer purchase behavior in C2C E-commerce in Chinese culture", Electronic Markets, Vol. 22 No. 3, pp.143-154. 